\title{
Global Properties of High Pressure Flux Conserving Tokamak Equilibria
}

\author{
J. F. Clarke \\ D. J. Sigmar
}




\section{DISCLAIMER}

This report was prepared as an account of work sponsored by an agency of the United States Government. Neither the United States Government nor any agency Thereof, nor any of their employees, makes any warranty, express or implied, or assumes any legal liability or responsibility for the accuracy, completeness, or usefulness of any information, apparatus, product, or process disclosed, or represents that its use would not infringe privately owned rights. Reference herein to any specific commercial product, process, or service by trade name, trademark, manufacturer, or otherwise does not necessarily constitute or imply its endorsement, recommendation, or favoring by the United States Government or any agency thereof. The views and opinions of authors expressed herein do not necessarily state or reflect those of the United States Government or any agency thereof. 


\section{DISCLAIMER}

Portions of this document may be illegible in electronic image products. Images are produced from the best available original document. 
Printed in the United States of America: Available from National Technical Information Service

U.S. Department of Commerce

5285 Port Royal Road, Springfield, Virginia 22161

Price: Printed Copy Microfiche $\$ 2.25$

\subsection{0}

This report was prepared as an account of work sponsored by the United States Government. Neither the United States nor the Energy Research and Development Administration/United States Nuclear Regulatory Commission, nor any of their employees, nor any of their contractors, subcontractors, or their employees, makes any warranty, express or implied, or assumes any legal liability or responsibility for the accuracy, completeness or usefulness of any information, apparatus, product or process disclosed, or represents that its use would not infringe privately owned rights. 
ORNL/TM-5599

Contract No. W-7405-eng-26

GLOBAL PROPERTIES OF HIGH PRESSURE

FLUX CONSERVING TOKAMAK EQUILIBRIA

J. F. Clarke

Oak Ridge National Laboratory

D. J. Sigmar

Massachusetts Institute of Technology

Cambridge, Massachusetts 02139

THERMONUCLEAR DIVISION

AUGUST 1976

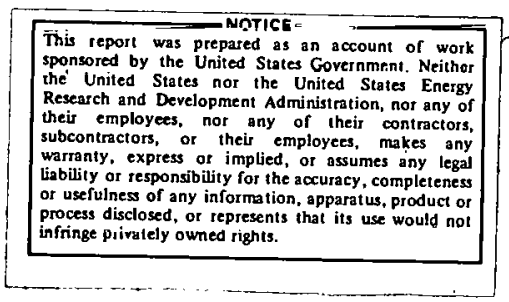

OAK RIDGE NATIONAL LABORATORY

Oak Ridge, Tennessee 37830

operated by

UNION CARBIDE CORPORATION

for the

ENERGY RESEARCH AND DEVELOPMENT ADMINISTRATION 


\section{THIS PAGE}

\section{WAS INTENTIONALLY LEFT BLANK}


CONTENTS

ACKNOWLEDGEMENTS $\quad v$

$\begin{array}{ll}\text { ABSTRACT } & 1\end{array}$

I. THE RELATIONSHIP OF PLASMA HEATING AND MHD EQUILIBRIUM 1

II. MHD EQUILIBRIUM RELATIONSHIPS $\quad 4$

III. ANALYTIC METHOD FOR OBTAINING ARBITRARY BETA MHD EQUILIBRIA 5

IV. DETERMINATION OF PARAMETERS SPECIFYING THE HIGH BETA EQUILIBRIUM 11

V. PROPERTIES OF FLUX CONSERVING HIGH BETA EQUILIBRIA 12

VI. CONCLUSIONS OF AXISYMMETRIC HIGH BETA EQUILIBRIUM ANALYSIS 14

$\begin{array}{ll}\text { REFERENCES } & 17\end{array}$ 
THIS PAGE

\section{WAS INTENTIONALLY LEFT BLANK}




\section{ACKNOWLEDGMENT}

We thank L. A. Berry and H. P. Furth for their invaluable criticism of the initial formulation of the ideas contained in this paper. One of the authors (DJS) is grateful to Prof. V. D. Shafranov for several discussions of the subject. 
GLOBAL PROPERTIES OF HIGH PRESSURE

FLUX CONSERVING TOKAMAK EQUILIBRIA*

J. F. Clarke.

Oak Ridge National Laboratory

Oak Ridge, Tennessee 37830

and

D. J. Sigmar

Massachusetts Institute of Technology

Cambridge, Massachusetts 02139

\section{ABSTRACT}

An approximate analytic theory is developed to calculate the poloidal beta $\beta_{I}$ and the diamagnetic parameter $\mu_{I}$ for a sequence of axisymmetric toroidal MHD equilibria confining high pressure plasmas $[\beta \sim \ddot{\theta}(a / R)]$ under the constraint of flux conservation. To satisfy the equilibrium equations, the plasma current must be increased with pressure as $\mathrm{p}^{1 / 3}$ and previously, calculated equiltbrium limits on poloidal beta are avoided.

I. THE RELATIONSHIP OF PLASMA HEATING AND MHD EQUILIBRIUM

Successful auxiliary heating of thermonuclear plasmas to ignition requires a characteristic heating time $\tau_{h}$ shorter than the energy containment time $\tau_{E}$. Using high power neutral particle injection, Tokamak experiments with

$$
\tau_{A}<\tau_{h} \leq \tau_{E}
$$


where $\tau_{A}$ is the Alfven-time, have been conducted (ORMAK) and a number of future devices (PLT, ORMAK Upgrade, TFTR) will satisfy this criterion. Experimental evidence so far (e.g., ATC, Tuman) indicates

$$
\tau_{E}<\tau_{p o 1}
$$

where $\tau_{\text {pol }}$, the poloidal skin penetration time; is given by

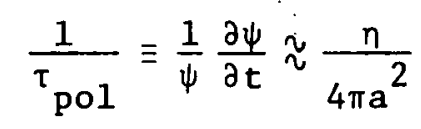

with $\psi$ the poloidal magnetic flux, $n$ the resistivity and a the minor plasma radius. (The experimentally effective $n$ tends to be $\leqslant 5$ times the Spitzer value.) Using the classical value (2b) and Pfirsch-Schlüter heat conduction scaling for $\tau_{E}$, one obtains

$$
\tau_{E} / \tau_{p o 1}=\left(2 \sqrt{\frac{m_{e}}{m_{i}}} / q^{2} B\right) \ll 1,
$$

In theoretical accordance wtth (2a) [ $q$ and $\beta$ are defined below]. The combination of conditions ( 1 ) and (2a) necessitates the theoretical study of a series of neighboring MHD equilibrla under the constraint of poloidal flux conservation.

The toroidal magnetic flux $\phi \equiv 2 \pi \int \mathrm{d} r \mathrm{r}_{\phi}$ diffuses on a time scale slower than $\tau_{\text {pol }}$ by a factor $\beta \equiv 8 \pi \overline{\mathrm{p}} / \mathrm{B}_{\phi}{ }^{2}$. To show this we define $F(\psi) \equiv \mathrm{R}_{\phi}$, and recalling that quite generally

$$
\frac{\psi_{0}}{\mathrm{~F}} \frac{\mathrm{dF}}{\mathrm{d} \psi} \sim O(\beta)
$$

one obtains

$$
\frac{1}{\Phi} \frac{\mathrm{d} \Phi}{\mathrm{dt}} \approx \frac{1}{\mathrm{~F}} \frac{\mathrm{dF}}{\mathrm{dt}} \approx \frac{\beta}{\psi} \frac{\mathrm{d} \psi}{\mathrm{dt}}
$$


Thus certainly

$$
\left(\frac{1}{\Phi} \frac{\partial \Phi}{\partial t}\right)^{-1} \gg \tau_{h}
$$

and since the safety factor $q$ is given by

$$
q(\psi)=\frac{1}{2 \pi} \frac{d \Phi}{d \psi}
$$

one concludes that $\mathrm{q}(\psi)$ will be an invariant for these equilibria. In our own analysis we will take $q(\psi)$ to be determined by its value in the low beta initial state and examine the evolution of the plasma equilibrium as the pressure is raised.

The condition $\tau_{h}<\tau_{E}$ implies an adiabatic equation of state, augmented in this case by a heat and particle source term due to neutral injection. However, the present problem differs from the well-known "adiabatic compressor" problem ${ }^{1,2,3}$ in that the major radius $R$ remains essentlally constant and flux conservation is realized by imposing

$$
\frac{\mathrm{d} \psi_{0}}{\mathrm{dt}}=0
$$

where $\psi_{0}$ is the polnital flux at the fixed plasma boundary. To keep the analysis simple and analytically tractable we will drop the coupling between the adiabatic equation of state and the equilibrium equation and assume henceforth that the average plasma pressure $p(\psi)$ shall be a free parameter. This assumption is realistic in experimental devices with powerful auxiliary heating. In principle, therefore, we will solve the MHD equilibrium problem with $p(\psi)$ and $q(\psi)$ given. 


\section{MHD EQUILIBRIUM RELATIONSHIPS}

The principal macroscopic parameters characterizing the Tokamak equilibrium are ${ }^{4}$

$$
\begin{gathered}
\beta_{I}=2 \int \operatorname{pdV} /\left(I^{2} \cdot 2 \pi R_{c}\right) \\
\mu_{I}=2 \int d V \frac{1}{8 \pi}\left(B_{\phi_{0}}^{2}-B_{\phi}^{2}\right) /\left(I^{2} \cdot 2 \pi R_{c}\right) \\
\ell_{i}=2 \int d V \frac{1}{8 \pi} B_{p}^{2} /\left(I^{2} \cdot 2 \pi R_{c}\right)
\end{gathered}
$$

where $I=I\left(\psi_{0}\right)$ is the total current inside the circular flux surface boundary $\psi=\psi_{0}$ with major radius $R_{c} \cdot B_{\phi}, B_{p}$ are the toroidal/poloidal magnetic fields and $B_{\phi_{0}}$ is the vacuum toroidal magnetic field. ${ }^{B_{I}}$ measures the poloidal beta, $\mu_{I}$ the plasma diamagnetism and $\ell_{i}$ the internal inductivity (inductance/cm gaussian) of the plasma column, a geometric factor of $O(1)$ determined by the shape of the current profile.

For a complete solution of the equilibrium problem one must solve the Grad-Shafranov Equation

$$
\Delta^{*} \psi / R^{2}=-4 \pi P^{\prime}(\psi)-F F^{\prime}(\psi) / R^{2}
$$

where $F$ has to be expressed through $q(\psi)$ using

$$
\mathrm{q}(\psi)=\frac{1}{2 \pi} \frac{\mathrm{d} \phi}{\mathrm{d} \psi}=F V^{\prime}(\psi)\left\langle\mathrm{R}^{-2}\right\rangle / 4 \pi^{2}
$$

Here,

$$
V^{\prime}(\psi)\left\langle R^{-2}\right\rangle / 2 \pi=\oint_{\psi} \frac{d \ell}{B_{p}} R^{-2},
$$

where $R^{\prime} B_{p}=|\nabla \psi|$ closes this set of equations. (These equations are conveniently derived in Callen and Dory. ${ }^{5}$ ) 
In principle, the calculation of this flux average can be facilitated by an expansion of the flux function

$\psi=s\left(\rho^{2}, \theta\right)=s_{\text {circ. }}\left(\rho^{2}\right)+s_{\text {ellip. }}\left(\rho^{2}, \theta\right)+s_{\text {triang. }}\left(\rho^{2}, \theta\right)+\cdots(5)$

where $(\rho, \theta)$ are suitable polar coordinates inside the circular flux shell and the RHS is developed in the deviation from a circular flux surface cross section, in powers of the small aspect ratio $\varepsilon=a / R_{c} \cdot A$ hierarchy of equations for $\mathrm{S}_{\text {circ. }}, \mathrm{S}_{\text {ellip. }}, \mathrm{S}_{\text {triang. }}$. can be generated from Eq. (4a) by a multipole expansion. 6

In practice, if one is content with a knowledge of the global parameters $\beta_{I}$ and $\mu_{I}$ of Eqs. (3), the problem can be simplified substantially by using two fundamental equations, viz. the integral form of the virial theorem and the equilibrium equation.

When evaluated on the outer flux surface of an axisymmetric toroidal plasma, these equations assume the form

$$
\begin{gathered}
\int d V\left[3 p+\frac{1}{8 \pi}\left(B_{p}^{2}+B_{\phi}^{2}-B_{\phi_{0}}^{2}\right)\right]=\int \frac{1}{8 \pi} B_{p}^{2} \underline{n} \cdot \underline{r} d s_{n} \\
2 \pi \int d s_{\phi}\left[p+\frac{1}{8 \pi}\left(B_{p}^{2}+B_{\phi_{0}}^{2}-B_{\phi}^{2}\right)\right]=\int \frac{1}{8 \pi} B_{p}^{2} \underline{n} \cdot \underline{e}_{x} d s_{n}
\end{gathered}
$$

where $d S_{n}$ is a flux surface element, $d S_{\phi}$ a cross sectional element, and $\underline{\mathrm{r}}$ and $\underline{\mathrm{e}} \mathrm{x}$ are depicted in Fig. 1 .

III. ANALYTIC METHOD FOR OBTAINING ARBITRARY BETA MHD EQUILIBRIA

As shown by Shafranov, ${ }^{4}$ for a circular flux shell of minor radius a, these two relationships reduce to 


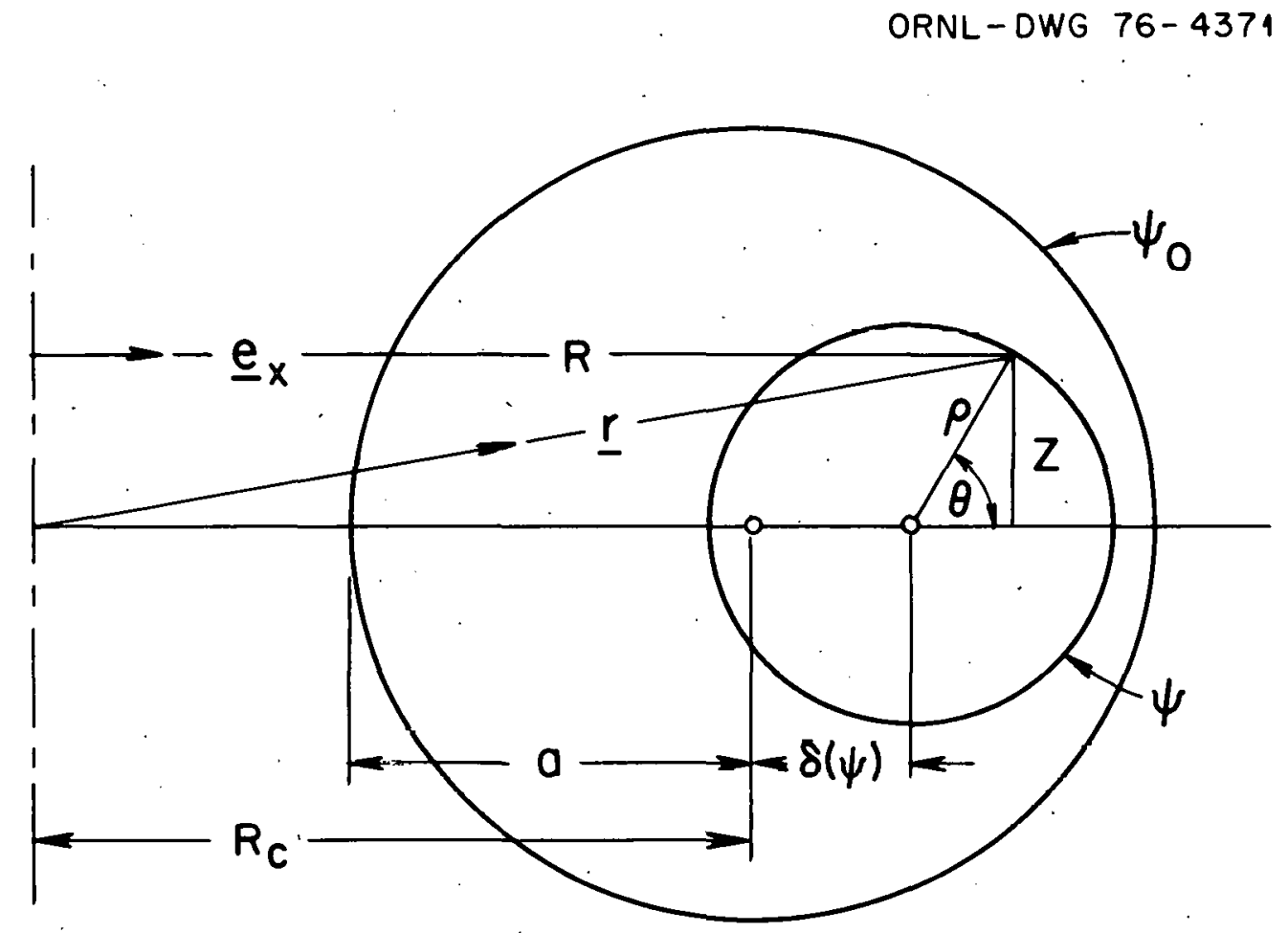

Fig. 1. Circular flux surface model geometry. 


$$
\begin{gathered}
3 \beta_{I}+l_{i}-\mu_{I}=2\left(S_{1}+S_{2}\right) \\
\beta_{I}+l_{i}+\mu_{I}=2 S_{2}
\end{gathered}
$$

whence

$$
\begin{aligned}
& \beta_{I}=S_{2}+\frac{S_{1}}{2}-\frac{\ell_{i}}{2} \\
& \mu_{I}=S_{2}-\frac{S_{1}}{2}-\frac{\ell_{i}}{2}
\end{aligned}
$$

Here

$$
\begin{aligned}
& 2 \pi I^{2} R_{C} S_{1}=\oint_{\psi_{0}} \frac{1}{8 \pi} B_{p}^{2} a d S_{n} \\
& 2 \pi I^{2} S_{2}=\oint_{\psi_{0}} \frac{1}{8 \pi} B_{p}^{2} \cos \theta d S_{n}
\end{aligned}
$$

where

$$
d S_{n}=2 \pi R_{c}(1+\varepsilon \cos \theta) a d \theta
$$

and we have neglected higher order terms in $a / R_{c}$. In these equations the total plasma current is given by

$$
I\left(\psi_{0}\right)=V^{\prime}(\psi)\left\langle\mathrm{B}_{\mathrm{p}}^{2}\right\rangle_{\psi_{0}} / 8 \pi^{2}
$$

Since we are treating the average pressure $\bar{p}$ as a variable controlled by auxiliary heating, Eq. (7a) should be looked upon as a relationship connecting the variable $\bar{p}$ with the surface integrals $\left\langle B_{p}^{2}\right\rangle_{\psi_{0}}, s_{1}$ and $s_{2}$. Once these are determined, Eq. (7b) yields $\mu_{I}$ as a function of $\bar{p}$ and $\ell_{i} \cdot$

Since the problem centers around the calculation of the surface averages $(8 \mathrm{a}, \mathrm{b}, \mathrm{c})$ at the circular plasma boundary $\psi=\psi_{0}=$ const, 
it is justifiable to drop the higher order noncircular terms in (5) and adopt the following circular flux surface approximation, describing a set of nested toroidal flux surfaces with circular cross section

$$
\psi=S_{i}\left(\rho^{2}\right), \rho^{2}=\left(R-R_{\psi}\right)^{2}+z^{2}, R_{\psi}=R_{c}+\delta(\psi)
$$

where $R_{\psi}$ extends to center of the circular flux tube $\psi\left(\rho^{2}\right)$, shifted from the geometric center $R_{c}$ by an amount $\delta(\psi)$, as shown in Fig. 1 .

This model equilibrium contains only two arbitrary functions $S\left(\rho^{2}\right)$ and $\delta(\psi)$. We shall determine the function $S$ from flux conservation and the parameter $\delta(\psi)$ or, more precisely, $\delta^{\prime}(\psi) \equiv \partial \delta / \partial \psi$ from Eq. (7a) after the surface integrals are performed. Had we defined a more complicated model.flux function with additional free parameters such as ellipticity, we would have required additional moments of the plasma force balance equations to determine them. 6

It follows from Fr. (9) that in our simple model

$$
\begin{aligned}
& \mathrm{R}_{\mathrm{p}}=|\nabla \psi|=2 \rho \dot{\mathrm{S}} / \mathrm{D}, \\
& \mathrm{B}_{\mathrm{p}}=2 \ddot{\varepsilon} \dot{\mathrm{S}} /(1+\tilde{\varepsilon} \cos \theta) \mathrm{D}
\end{aligned}
$$

where $D=1+d \cos \theta, d=2 \rho \dot{S} \delta^{\prime}(\psi)$, and

$$
\dot{S}=\frac{d \psi}{d \rho}{ }^{2}, \tilde{\varepsilon}=\frac{\rho}{R_{\psi}}, R=R_{\psi}(1+\tilde{\varepsilon} \cos \theta)
$$

The volume inside a flux surface $\psi=$ const is $V(\psi)=2 \pi^{2} \rho^{2} R_{\psi}$. In this flux model, the flux average becomes

$$
\frac{V^{\prime}\langle X\rangle}{(2 \pi)^{2}}=\frac{R_{\psi}}{2 \dot{S}} \int \frac{d \theta}{2 \pi} D(1+\tilde{\varepsilon} \cos \theta) X
$$


The integrations $(8 c),(4 c)$ are elementary and yield

$$
\begin{aligned}
& I(\psi)=\rho \dot{S} \tilde{\varepsilon}\left(1+\frac{\tilde{\varepsilon} \mathrm{d}}{2}+\cdots\right) / \sqrt{1-\mathrm{d}^{2}} ; \\
& V^{\prime}\left\langle\mathrm{R}^{-2}\right\rangle / 4 \pi^{2}=\frac{\tilde{\varepsilon}}{2 \rho \dot{S}}\left(1-\frac{1}{2} \tilde{\varepsilon} \mathrm{d}+\cdots\right) .
\end{aligned}
$$

The dots indicate higher order terms in $\varepsilon$.

As the flux surfaces shift outward under the increased plasma pressure in the high beta regime, one expects that $|d| \rightarrow 0(1)$ at $\psi=\psi_{0}$. Concomitantly, the poloidal field (10a) has a non-expandable dependence on $\cos \theta$ in marked contrast to the widely used low beta mode $1^{7}$

$$
\mathrm{B}_{\mathrm{p}}=\mathrm{B}_{\mathrm{p} 0}(1+\varepsilon \Lambda \cos \theta)
$$

As long as flux is conserved, the singularity can only be approached asymptotically as the pressure is raised. As will be shown below, it is the correct treatment of the dependence of $B_{p}$, which eliminates any equilibrium limit on the poloidal beta. The remaining surface integrals are

$$
\begin{gathered}
\frac{\mathrm{a}}{8 \pi} \oint_{\psi_{0}} \mathrm{~B}_{\mathrm{p}}^{2} \mathrm{dS} \mathrm{S}_{\mathrm{n}}=\mathrm{a}^{2} 2 \pi \mathrm{R}_{\mathrm{c}}(\tilde{\varepsilon} \dot{\mathrm{S}})^{2}\left(\frac{1+\tilde{\varepsilon} \mathrm{d}}{\left(1-\mathrm{d}^{2}\right)^{3 / 2}}\right) \\
\frac{1}{8 \pi} \oint_{\psi_{0}} \mathrm{~B}_{\mathrm{p}}^{2} \cos \theta \mathrm{dS}_{\mathrm{n}}=\mathrm{a} 2 \pi \mathrm{R}_{\mathrm{c}}(\tilde{\varepsilon} \dot{\mathrm{S}})^{2}\left(-\frac{\mathrm{d}+\tilde{\varepsilon}}{\left(1-\mathrm{d}^{2}\right)^{3 / 2}}+\frac{\tilde{\varepsilon}}{\mathrm{d}^{2}} \cdot \frac{1-\sqrt{1-\mathrm{d}^{2}}}{\sqrt{1-\mathrm{d}^{2}}}\right)
\end{gathered}
$$


In summary,

$$
\begin{gathered}
S_{1} \cdot I^{2}=(a \tilde{\varepsilon} \dot{S})^{2} \frac{1+\tilde{\varepsilon} d}{\left(1-d^{2}\right)^{3 / 2}} \\
S_{2} \cdot I^{2}=\frac{R_{c}}{a}(a \tilde{\varepsilon} \dot{S})^{2}\left\{-\frac{d+\tilde{\varepsilon}}{\left(1-d^{2}\right)^{3 / 2}}+\frac{\tilde{\varepsilon}}{d^{2}} \frac{1-\sqrt{1-d^{2}}}{\sqrt{1-d^{2}}}\right\}
\end{gathered}
$$

and from (11a)

$$
I^{2}=(\rho \dot{S} \tilde{\varepsilon})^{2} \frac{\left(1+\frac{\tilde{\varepsilon} d}{2}\right)^{2}}{1-d^{2}}
$$

The $\left(1-d^{2}\right)^{-n}$ terms will be shown below to dominate the high beta equilibrium properties. For example, combining (12a) and (12c),

$$
s_{1} \simeq\left(1-d^{2}\right)^{-1 / 2}>>1 \cdots
$$

in the high beta flux conserving equllibrium vs. $s_{1} \sim 0(1)$ in Ref. 4.

Defining a pressure variable normalized by the initial low beta toroidal current

$$
\bar{\beta}_{I}=2 \int d V p / 2 \pi R_{c} I_{i}^{2}
$$

we find for $\beta_{I}$ defined in (3a), using (12c)

$$
\frac{B_{I}}{\bar{B}_{I}}=\frac{\dot{s}^{2}}{\dot{S}^{2}} \frac{\left(i+\frac{\varepsilon d}{2}\right)^{2}}{\left(1+\frac{\varepsilon d}{2}\right)^{2}} \cdot \frac{1-d^{2}}{1-d_{i}^{2}}
$$

where the subscript $i$ stands for the initial value and $\varepsilon=a / R_{c}$. Al1 quantities on the RHS are evaluated at $\psi=\psi_{0}$. 


\section{DETERMINATION OF PARAMETERS SPECIFYING THE HIGH BETA EQUILIBRẼÜM}

Having expressed $I, \beta_{I}, S_{1}$ and $S_{2}$ in terms of $S\left(\rho^{2}\right)$ and $d(\psi)$, we must determine these latter two quantities for the flux conserving equilibrium.

From Eqs. $(7 a, b)$ and $(12 a, b)$ it is clear that large increases in $\beta$ can be produced if $d+1$. One expects a small decrease in $\ell_{i}$ as beta is increased $(d \rightarrow 1)$ since the denominator of Eq. $3 c$ becomes large as beta is increased while the numerator which depends only on an integral over $\left(1-d^{2}\right)$ remains finite. Qualitatively this follows since increasing beta in a flux conserving system tends to drive a current increasing toward the surface [Eq. (1la)]. Thus, the external magnetic field is increased more than the internal field. Numerical calculations 8 confirm that $\ell_{i}$ does not have a strong dependence on beta and in what follows we shall approximate it by its low beta value.

The functional form of $S\left(\rho^{2}\right)$ is specified by the invariance of $\mathrm{q}(\psi)$ in a flux conserving system. From Eqs. (4b) and (11b), $q(\psi)$ can be written

$$
q(\psi)=\frac{F}{2 \dot{S} R_{c}}\left\{1-\frac{\tilde{\varepsilon} d}{2}\right\}
$$

Now, in general, $F$ is a constant plus an order $\beta$ term. Thus, order unity variations in $q$ can only be produced by changes in $\dot{\mathrm{s}}$. Conversely, since $q$ is an invariant on each $f l u x$ surface as $\beta$ is increased in a flux conserving tokamak, $\dot{s}$ must also be an invariant to zero order in beta. Finally, for simplicity, we will specialize to the case of $q$ constant on all flux surfaces which implies that $\dot{S}$ is a constant to zero order in $B$, i.e., 


$$
S=\psi_{0} \rho^{2} / a^{2}+0(\beta)
$$

We will neglect the change in the functional form of $S$ as the pressure is increased.

The above arguments leading to the specification of the function $S$ are valid near the surface where the circular shape of the flux surfaces is guaranteed by the boundary condition. As shown by numerical calculation, ${ }^{8}$ when the beta is raised in a flux conserving tokamak, strong deformation of the initially circular flux surfaces occurs in the plasma interior and Eq. (15) has a more complicated form. Fortunately, for the present work, we require a knowledge of $S$ only near the surface where Eq. (15) is sufficiently accurate.?

\section{PROPERTIES OF FLUX CONSERVING HIGH BETA EQUILIBRIA}

We are thus justified to approximate $\ell_{i}$ and $\dot{S}$ by their initial low beta values. Moreover, if we retain the shearfree model $q=q_{0}$, $\dot{\mathrm{s}} \simeq \psi_{0} / \mathrm{a}^{2}$ can be taken for all values of $B$. Then Eqs. $(7 \mathrm{a}, \mathrm{b})$ can serve to determine $\beta_{I}$ and $\mu_{I}$ as follows. Approximating (13) by

$$
\beta_{I}=\bar{\beta}_{I}\left(1-d^{2}\right)
$$

since $d_{i} \sim \varepsilon, \beta_{I}$ becomes uniquely dependent on $d^{2}$. Using Eqs. (12), (7a) assumes the form

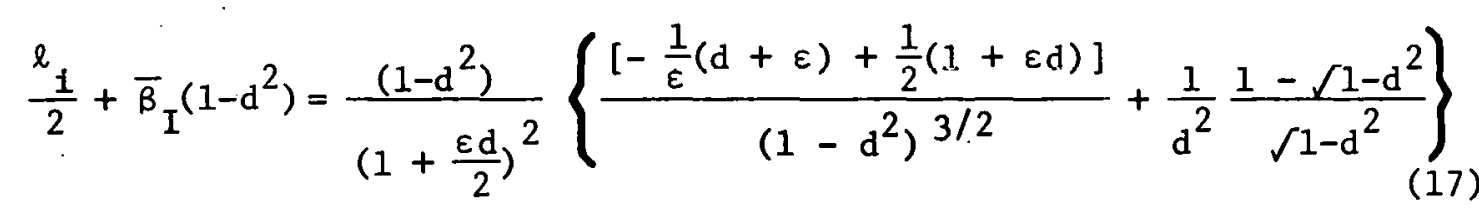


which yields the desired relation between the unknown parameter $d$ and the pressure variable $\bar{\beta}_{I}$. In the high beta limit this relation reduces to

$$
\bar{\beta}_{I} \simeq\left(-\frac{d}{\varepsilon}\right)\left(1-d^{2}\right)^{-3 / 2}
$$

Solving for $d$, the inversion of (18) for high beta is

$$
-d \simeq\left[1-\frac{1}{3} \cdot\left(\varepsilon \bar{\beta}_{I}\right)^{-2 / 3}\right]^{3 / 2}
$$

showing that $\mathrm{d}^{2} \rightarrow 1$ for $\bar{\beta}_{I} \rightarrow \infty$ as discussed above. The low beta limit follows trivially from (16), viz. $\beta_{I} \simeq \bar{\beta}_{I}$.

To calculate $\beta_{I}$ as a function of the pressure variable $\bar{\beta}_{I}$ in the high beta limit, we use Eqs. (16) and (19) to obtain

$$
\beta_{I} / \bar{\beta}_{I} \simeq 1-d^{2}=1-\left[1-\frac{1}{3} \cdot\left(\varepsilon \bar{\beta}_{I}\right)^{-2 / 3}\right]^{3}
$$

In the regime $\varepsilon \bar{\beta}_{I}>1$ this can be expanded to yield

or

$$
\beta_{I} / \bar{\beta}_{I} \simeq\left(\varepsilon \bar{\beta}_{I}\right)^{-2 / 3}
$$

$$
\beta_{I}=\varepsilon^{-2 / 3}\left(\bar{\beta}_{I}\right)^{1 / 3}
$$

The pressure dependence of the plasma current follows immediately. From $(12 c)$ and $\dot{s} \simeq \psi_{0} / a^{2}$

$$
I\left(\psi_{0}\right)=\left\{\begin{array}{lr}
\frac{\psi_{0}}{R_{c}} & \text { low } \beta \\
\frac{\psi_{0}}{R_{c}}\left(1-d^{2}\right)^{-1 / 2} \simeq \frac{\psi_{0}}{\bar{R}_{C}}\left(\varepsilon \bar{\beta}_{I}\right)^{1 / 3} & \text { high } \beta
\end{array}\right.
$$

From (7b), one obtains for the diamagnetic parameter

$$
\begin{aligned}
& \mu_{I}+\frac{l_{i}}{2}=-\left(1+\frac{\varepsilon d}{2}\right)^{-2}\left[\frac{1}{\varepsilon}(d+\varepsilon)+\frac{1}{2}(1+\varepsilon d)\right] / / \sqrt{ } 1-d^{2} \\
& +\mathrm{d}^{-2}\left(1+\frac{\varepsilon \mathrm{d}}{2}\right)^{-2}\left[\sqrt{1-\mathrm{d}^{2}}-\left(1-\mathrm{d}^{2}\right)\right]
\end{aligned}
$$


In the high beta regime $\left(-\mathrm{d} / \varepsilon>1, \mathrm{~d}^{2} \rightarrow 1\right)$

$$
\mu_{I}+\frac{\ell_{i}}{2}+-\frac{d}{\varepsilon}\left(1-d^{2}\right)^{-1 / 2}=\left(1-d^{2}\right) \bar{B}_{I}>0 .
$$

where the dependence of $d$ on pressure is given in (19). Comparing this with (16) shows $\mu_{I} \rightarrow \beta_{I}$ in asymptotic agreement ${ }^{9}$ with Eq. (40) of Ref. 4. Thus, from $(22 b),(1 / 8 \pi) \int d V\left(B_{\phi_{0}}^{2}-B_{\phi}^{2}\right)>0$, showing the high beta diamagnetism since $B_{\phi_{0}}$ is the toroidal field for zero plasma pressure.

An upper bound for $\mu_{I}$ exists as $\int d V B_{\phi}^{2} / B_{\phi_{0}}^{2} \rightarrow 0$, or equivalently, $B \rightarrow 1$. At $\beta=1$, or $\bar{B}_{I}=q^{2} / \varepsilon^{2}$, from Eq. (19)

$$
d^{2}=1-\varepsilon^{2 / 3} \cdot q^{-4 / 3}
$$

and from Eq. (20b)

$$
\beta_{I}=q^{2 / 3} \cdot \varepsilon^{-4 / 3}
$$

The exact behavior of $\beta_{I}, \mu_{I}$ and the plasma current $I\left(\psi_{0}\right)$ as a function of the pressure variable $\bar{\beta}_{I}$ is shown in Fig. 2. Since $\bar{\beta}_{I} \equiv$ $q^{2} B / \varepsilon^{2}$ and the maximum value of $\beta$ is one, the maximum value of $\bar{\beta}_{I}$ in the figure is dependent on the choice of $q$.

Setting $\mu_{I}$ in $(22 a)$ equal to zero, the change from para-to diamagnetism occurs for $-d=5 / 4 \cdot \varepsilon$. Inserting this value for $d$ in (17) results in $\bar{\beta}_{I} \simeq 1$ as expected. In the low $\beta$ limit $[d \sim 0(\varepsilon)]$, Eqs. (17) and (22a) combine to yleld $\mu_{I}=\beta_{I}-S_{1}$, where from $(12 d), S_{1} \simeq 1$, in agreement with Eq. (41) of Ref. 4.

\section{CONCLUSIONS OF AXISYMMETRIC HIGH BETA EQUILIBRIUM ANALYSIS}

1. Increasing the average pressure $\int \mathrm{dVp} / \mathrm{V}$ (by means of auxiliary heating) on a flux conserving time scale, the equilibrium equations of 


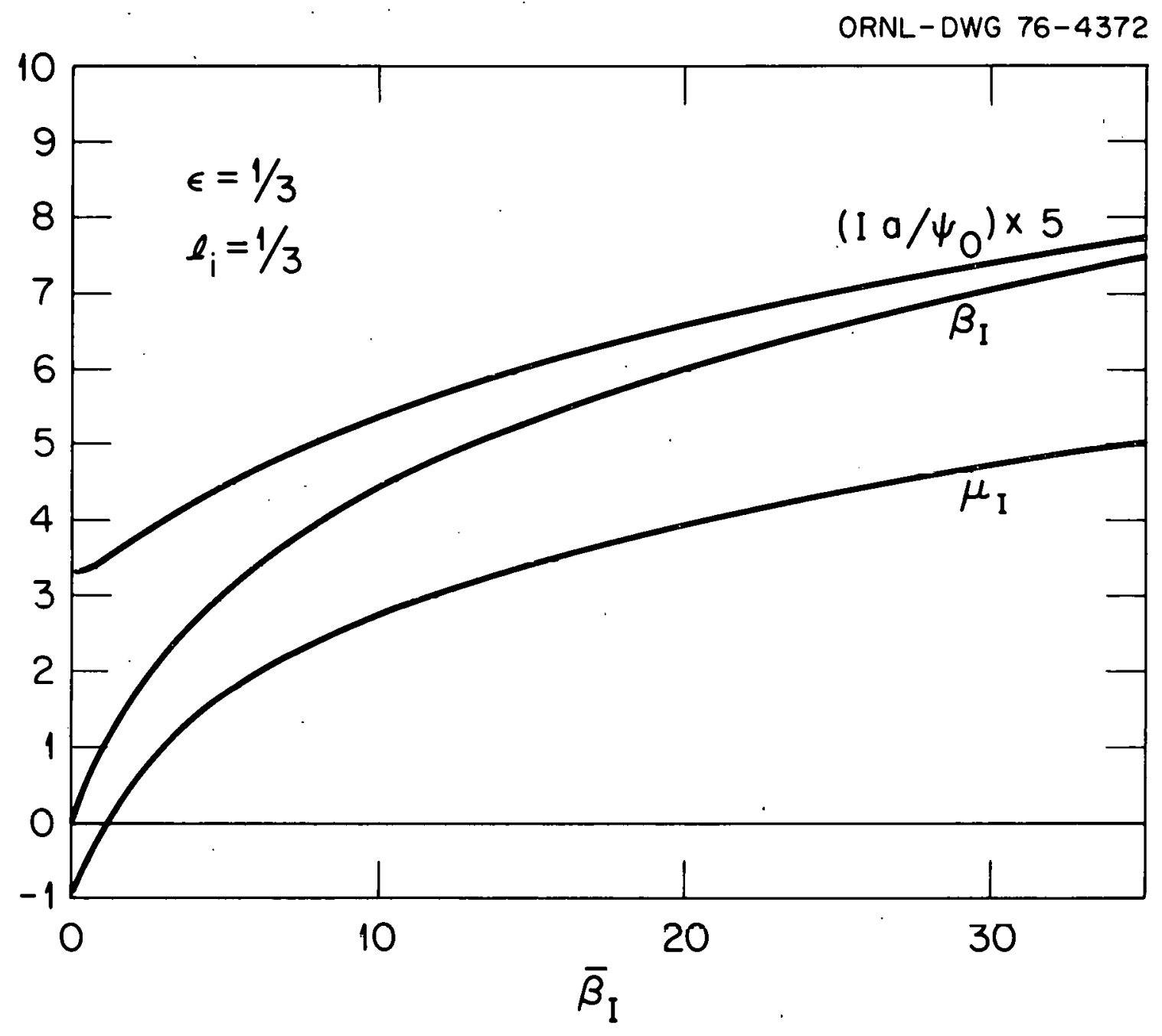

Fig. 2 The behavior of $\beta_{I}, \mu_{I}$ and $I$ are shown as a function of $\bar{\beta}_{I}$ for $\varepsilon=1 / 3, \ell_{i}=1 / 2$. 
an axisymmetric toroidal plasma permit a continuous transition from low to arbitrarily high values of beta (Ėqs. 16 and 17).

2. In a flux conserving equilibrium, the plasma current must be allowed to increase with pressure as $\left(\varepsilon \bar{\beta}_{I}\right)^{1 / 3}$ [Eq. (21b)].

3. Consequently, the poloidal beta grows slower than linearly with pressure, (Eq. 20b), and the often used scaling relation $B_{I}=q^{2} B / \varepsilon^{2}$ does not apply for the flux conserving tokamak. It is replaced by (20b) asymptotically.

4. The flux conserving equilibria considered in this paper do not permit formation of a second magnetic axis as can be seen from Eq. (10a):

$$
\mathrm{B}_{\mathrm{P}}\left(\psi=\psi_{0}, \theta=\pi\right)=\frac{2 \varepsilon\left(\mathrm{d} \psi / \mathrm{d} \rho^{2}\right) \psi_{0}}{(1-\mathrm{d})(1-\varepsilon)}
$$

Since from (17) and (23a), $0<-d<1, B_{p}$ can therefore not vanish. This confirms the physical notion that the topology of flux surfaces cannot change if flux is conserved. Thus, there is no equilibrium limit such as implied by the condition $\beta_{I}<\varepsilon^{-1}$ obtained for nonflux conserving equilibria at constant plasma current. 10

5. In the high beta limit, the diamagnetic parameter $\mu_{I}$ approaches $\beta_{I}$, implying confinement by the toroidal diamagnetic well. There are no equilibrium limits short of the ultimate limit at $\beta=1$ where $\beta_{I}=$ $q^{2 / 3} \varepsilon^{-4 / 3}(E q \cdot 23 b)$. 
REFERENCES

1. H. P. Furth, S. Yosh1kawa, Phys. Fluids 13, 2593 (1970).

2. J. M. Greene, J. L. Johnson, K. E. Weimer, Phys. Fluids $\underline{14}, 671$ (1971).

3. H. Grad, P. N. Hu, D. C. Stevens, Proc. U.S. Natl. Ac. Sci. 72,3789 (1975).

4. V. D. Shafranov, Plasma Phys. 13,757 (1971).

5. J. D. Callen, R. A. Dory, Phys. Fluids 15, 1523 (1972).

6. L. E. Zakharov, V. D. Shafranov, Sov. Phys., Tech. Phys. 18, 151 (1973)

7. V. D. Shafranov in Revs. Plas. Phys., Vol. II, 125, Consultants Bureau, N. Y. (1966).

8. R. A. Dory and Y-K. M. Peng, to be published as ORNL/TM-5555, "High Pressure, Flux-Conserving Tokamak Equilibria,"; also to be pub1tshed in Nuclear Fusion.

9. Note, however, that owing to Eq. (12d), Eq. (41) of Ref. 4 is not valid for high beta flux conserving equilibria for the reason given after Eq. (11b).

10. S. Yoshikawa, "Limitation of Pressure in Tokamak P1asmas, MATT-1261, (June 1976). 


\section{THIS PAGE}

\section{WAS INTENTIONALLY \\ LEFT BLANK}




$\begin{aligned} \text { 1. } & \text { L. A. Berry } \\ \text { 2. } & \text { J. D. Callen } \\ \text { 3-12. } & \text { J. F. Clarke } \\ \text { 13. } & \text { F. L. Culler } \\ \text { 14. } & \text { R. A. Dand1 } \\ \text { 15. } & \text { C. A. Flanagan } \\ \text { 16. } & \text { P. N. Haubenreich } \\ \text { 17. } & \text { G. G. Kelley } \\ \text { 18. } & \text { H. M. Long } \\ \text { 19. } & \text { F. C. Maienschein } \\ \text { 20. } & \text { O. B. Morgan } \\ \text { 21. } & \text { H. Postma }\end{aligned}$

1. L. A. Berry

3-12. J. F. Clarke

13. F. L. Culler

14. R. A. Dand1

15. C. A. Flanagan

16. P. N. Haubenreich

19. F. C. Maienschein

21. H. Postma

\author{
22. M. Roberts \\ 23. M. W. Rosenthal \\ 24. D. Steiner \\ 25. L. D. Stewart \\ 26-27. Central Research Library \\ 28. Document Reference Section \\ 29. ORNL Patent Office \\ 30. Laboratory Records, RC \\ 31-32. Laboratory Records \\ 33. Thermonuclear Division Library \\ 34. CTR Reports Office
}

\section{External Distribution}

35. Director, Division of Research and Technical Support, USERDA-ORO

36. D. J. Anthony, General Electric Company, Energy Systems and Technical Division, 1 River Road, Schenectady, NY 12345

37. S. J. Buchsbaum, Executive Director, Research Communications Science Division, Bel1 Laboratory, Crawford Corner Road, Holmdel, NJ 07733

38. R. W. Bussard, 462 Santa Cecelia, Solana Beach, CA 92075

39. A. T. Christensen, Manager, Program Development, General Electric Company, 777 14th Street, N.W., Washington, DC 20005

40. R. W. Conn, Department of Nuclear Engineering, University of Wisconsin, Madison, WI 53706

41. E. C. Creutz, Assistant Director for Research, National Science Foundation, 1800 G. Street, N.W., Washington, DC 20550

42. S. O. Dean, Assistant Director for Confinement Systems, Division of Magnetic Fusion Energy, USERDA, Mail Stop G-234, Washington, DC 20545

43. E. Engelmann, Associazione Euratom-Chen Sulla Fusione, Centro Gas Ionizzati, C.P. 65 - 00044, Frascati, Rome, ITALY

44. S. Fernbach, Lawrence Livermore Laboratory, University of California, P. 0. Box 808, Livermore, CA 94551

45. H. K. Forsen, Exxon-Nuclear Company, 777 106th Avenue. N. E., Bellevue, Washington 98004

46. T, K. Fowler, Associate Director, Lawrence Livermore Laboratory, University of California, P. 0. Box 808, Livermore, CA 94551

47. J. P. Freidberg, Los Alamos Scientific Laboratory, Los Alamos, New Mexico 87544

48. H. P. Furth, Co-Head Experimental Division, Plasma Physics Laboratory, Princeton University, P. O. Box 451, Princeton, NJ 08540

49. F. C. Gilbert, Division of Military Application, USERDA, Washington, DC 20545 
50. M. B. Gottlieb, Director, Plasma Physics Laboratory, Princeton University, P. 0. Box 451, Princeton, NJ 08540

51. W. C. Gough, Electric Power Research Institute, 3412 Hillview Avenue, P. 0. Box 10412, Palo Alto, CA 94304

52. R. W. Gould, Department of Applied Physics, California Institute of Technology, Pasadena, CA 91109

53. J. N. Grace, Technical Project Officer, Division of Magnetic Fusion Energy, USERDA, Mail Stop G-234, Washington, DC 20545

54. H. Grad, Courant Institute, New York University, 251 Mercer Street, New York, NY 10012

55. R. C. Grim, Princeton Plasma Physics Laboratory, Princeton University

P. O. Box 451, Princeton, New Jersey, 08540

56. G. E. Guest, General Atomic Company. P. 0. Box 81608, San Diego, California 92138

57. F. A. Haas, Culham Laboratory, Abingdon Oxfordshire, UNITED KINGDOM

58. G. K. Hess, Jr., Senior Scientific Advisor, Division of Magnetic Fusion Energy, USERDA, Mail Stop G-234, Washington, DC 20545

59. R. L. Hirsch, Assistant Administrator for Solar, Geothermal and Advanced Energy Systems, Energy Research and Development Administration Washington, DC 20545

60. J. L. Johnson, Princeton Plasma Physics Laboratory, Princeton University, P. 0. Box 451, Princeton, New Jersey 08540

61. E. S. Keen, Boeing Company, 102 Tulsa Road, Oak Ridge, TN 37830

62. E. E. Kintner, Director, Division of Magnetic Fusion Energy, USERDA, Mai1 Stop G-234, Washington, DC 20545

63. C. Mercier, Center for Nuclear Studies, B.P. $\mathrm{n}^{\circ} 6-92260$, Fontenay-aux-Roses, FRANCE

64. B. Miller, Assistant Director for Research, Division of Magnetic Fusion Energy, USERDA, Mail Stop G-234, Washington, DC 20545

65. S. Mori, Thermonuclear Fusion Laboratory, Tokai Research Establishment, Japan Atomic Research Institute, Tokai-mura, Naka-gun, Ibaraki-ken, $319-11$, JAPAN

66. T. Ohkawa, General Atomic Company, P. 0. Box 81608, San Diego, CA 92212

67. M. Okabayaski, Princeton Physics Laboratory, James Forrestal Campus, Princeton University, Princeton, New Jersey 08540

68. D. Pfirsch, Max-Planck Institute for Plasma Physics, D-8046, Garching, Federa1 Republic of GERMANY

69. P. J. Reardon, Head of Tokamak Fusion Test Reactor, Plasma Physics Laboratory, Princeton University, P. 0. Box 451, Princeton, New Jersey 08540

70. F. L. Ribe, Division Leader, CTR Division, Los Alamos Scientific Laboratory, P. O. Box 1663, Los Alamos, NM 87544

71. D. J. Rose, Department of Nuclear Engineering, Massachusetts Institute of Technology, Cambridge, MA 02139

72. M. N. Rosenbluth, School of Natural Sciences, Princeton University, P. 0. Box 451, Princeton, New Jersey 08540

73. P. H. Rutherford, Princeton Plasma Physics Laboratory, Princeton University, P. 0. Box 451, Princeton, New Jersey 08540

74. V. D. Shafranov, Kurchatov Institute, Atomic Energy, 46 Ulitsa, Kurchatova, P. 0. Box 3402, Moscow D-182, USSR 
75. Z. Shapiro, Executive Assistant to the General Manager, Breeder Reactor Division, Westinghouse Electric Corporation, P. 0. Box 355, P1ttsburgh, PA 15230

76. T. H. Stix, Princeton Plasma Physics Laboratory, Princeton University, P. O. Box 451, Princeton, New Jersey 08540

77. J. B. Taylor, Culham Laboratory, Abingdon Oxfordshire, UNITED KINGDOM

78. A. Trivelpiece, Department of Physics \& Astronomy, University of Maryland, College Park, MD 20742

79. H. H. Woodson, Chairman, Department of Electrical Engineering, The University of Texas at Austin, Austin, TX 78712

80. M. Yoshikawa, Thermonuclear Fusion Laboratory, Tokai Research Establishment, Japan Atomic Research Insititute, Tokai-mura, Naka-gun, Ibaraki-ken, 319-11, JAPAN

81. S. Yoshikawa, Princeton Plasma Physics Laboratory, Princeton University, P. 0. Box 451, Princeton, New Jersey 08540

82-108. Technical Information Center, USERDA 